\title{
Is there a trade-off between free capital mobility, financial stability and fiscal policy flexibility in the EMU?
}

\author{
Rosaria Rita Canale $^{3} \cdot$ Paul De Grauwe ${ }^{1} \cdot$ Pasquale Foresti $^{1,2}{ }_{(D)}$. \\ Oreste Napolitano ${ }^{3}$
}

(C) The Author(s) 2017. This article is an open access publication

\begin{abstract}
The recent dynamics characterizing the Eurozone economy suggest the existence of a new policy trilemma faced by its member countries. According to this policy trilemma, there is a trade-off between free capital mobility, financial stability and fiscal policy flexibility. In this paper, we analyze the foundations of such a trade-off and, based on the data for 11 Eurozone countries, present an empirical investigation on the existence of the trilemma. The results highlight the existence of the trade-off, with some differences between member countries. The existence of this trilemma in the Eurozone provides arguments for implementing centralized financial supervision together with fiscal and monetary reforms that should strengthen the currency union.
\end{abstract}

Keywords EMU · Policy trilemma · Eurozone - Free capital mobility · Fiscal policy $\cdot$ Financial stability $\cdot$ Financial crisis

JEL Classification E61 $\cdot \mathrm{F} 41 \cdot \mathrm{C} 21 \cdot \mathrm{C} 23$

Pasquale Foresti

p.foresti@1se.ac.uk

Rosaria Rita Canale

canale@uniparthenope.it

Paul De Grauwe

P.C.De-Grauwe@1se.ac.uk

Oreste Napolitano

napolitano@uniparthenope.it

1 The London School of Economics and Political Science, London, UK

2 Coventry University, Coventry, UK

3 University of Naples "Parthenope", Naples, Italy 


\section{Introduction}

Many studies have highlighted the presence of a trade-off between some policy objectives. The most famous one is the open economy policy trilemma theorized in the Mundell-Fleming model (Mundell 1963; Fleming 1962). These authors have stressed that it is not possible to have simultaneously: fixed exchange rates, independent monetary policy and free capital mobility. Therefore, policy makers are forced to drop one of these objectives and fulfill only two of them. Alternatively, they can choose a combination of the three policy objectives in which none of them is fully achieved.

Member countries of the Eurozone do not face this trade-off anymore as the launch of the common currency and the creation of the ECB have naturally solved the impossible trinity by eliminating national and independent monetary policies. These countries decided to abandon monetary independence, let capitals move freely across the union, and share a common currency.

Nevertheless, the recent economic upheavals that have hit the Eurozone have also been interpreted as the signals of the existence of other trade-offs between policy objectives in the EMU. Then, other trilemmas, specific for the Eurozone, have been proposed by Pisani-Ferry (2012) and Obstfeld (2013). Despite their different approach to the problem, both contributions focus on the interactions between financial markets and fiscal policy and highlight the difficulties in reconciling the contemporaneous existence of capital market integration, financial stability and the ability to manage fiscal accounts.

Therefore, in this study we focus on a possible trade-off that should make it impossible to simultaneously achieve: (1) free capital mobility; (2) fiscal policy flexibility; and (3) financial stability. We can refer to this trade-off as the monetary union trilemma and it suggests that, in a currency union like the EMU, it is impossible for member countries to fully achieve all these three objectives simultaneously.

We analyze the theoretical and institutional foundations for the monetary union trilemma and empirically investigate the existence of such a trade-off in the countries of the Eurozone. We include 11 EMU member countries (Austria, Belgium, Finland, France, Germany, Greece, Ireland, Italy, Netherlands, Portugal and Spain) in our dataset and conduct our analysis on the basis of quarterly data spanning the period 1999q1-2012q4. The results support the idea of the existence of a relation between the policy variables, demonstrating that one of the policy objectives can be reached at the expenses of one of the others or a combination of two. This implies that the monetary union trilemma is binding in the Eurozone although we also show that some differences across member countries characterize its configuration. In our view, the existence of such a trade-off provides arguments for implementing centralized financial supervision together with fiscal and monetary reforms in order to build up a stronger currency union.

The paper is organized as follows. In Sect. 2 we explain the theoretical and institutional foundations for the monetary union trilemma, and how it applies to the Eurozone. In Sect. 3 we report the data used and show how the indicators to study the existence of the trade-off between the variables in the trilemma have been constructed. The results of the empirical analysis are reported and commented in 
Sect. 4. In Sect. 5 we analyze the robustness of our results. In Sect. 6 we conclude the paper and provide some policy implications.

\section{Currency unions and the monetary union trilemma}

According to the optimum currency areas (OCA) theory, financial market integration is one of the main criteria for a successful monetary union. The main justification supporting financial integration is that in its presence the impact of asymmetric shocks is diminished. A currency union is sustainable even under asymmetric shocks as long as its member countries are able to insure each other thanks to financial integration. This insurance acts through a risk-sharing mechanism between member countries (see Mundell 1973a, b; McKinnon 2004) when residents in one country hold claims on the dividends, interests and rental revenues from other countries. This should be able to reduce the degree of asymmetric impact of the shocks. Similar reasoning is followed by Ingram (1962) in stating that exchange rate adjustments are less needed under financial integration as the latter should be able to cushion temporary adverse disturbances thanks to capital flows. Moreover, financial integration should make the transmission of monetary policy smoother and more symmetric across member countries. These are all reasons that explain why strengthening financial openness has always been one of the main objectives of the EMU authorities.

Another important issue in a currency union relates to the conduct of fiscal policy. As long as there is not a substantial level of political integration, fiscal policies are conducted by national governments. Therefore, mechanisms able to safeguard fiscal policy coordination and discipline are necessary. To this aim, rules and institutions have been created in the Eurozone. Despite these common rules, due to the loss of the monetary instrument, fiscal policy is responsible for stabilizing the economy against asymmetric shocks in a currency union. Therefore, fiscal flexibility is a relevant policy objective for each member country. Nevertheless, in the EMU framework the smoothing of the cycle has to rely on automatic fiscal stabilizers rather than active policies (see Brunila et al. 2002).

Recent economic developments (financial and sovereign debt crises) suggest that a negative interaction between financial markets and fiscal policy can take place in the Eurozone. As shown by Ardagna (2009) and Foresti and Napolitano (2017), financial markets value fiscal discipline, as they react positively after fiscal consolidations and negatively after fiscal expansions. As a consequence, financial markets can constrain the fiscal policy choices. In a monetary union without a lender of last resort, with no centralized budget, with high level of capital mobility and no banking union, it can be argued that such influence can be even amplified, especially in periods of intense borrowing by member countries. Further support for this idea is provided by De Grauwe and Ji (2013), showing that during the sovereign debt crisis in the Eurozone, fiscal austerity has been the outcome of fear and panic in the financial market (with this impact amplified by free capital mobility). As a result, fiscal policy decisions in Europe have been constrained by the dynamics of the financial market. 
These interactions between financial markets and fiscal policy can be synthesized in the existence of a trade-off according to which it is hard to reconcile the contemporaneous existence of free capital flows, financial stability and the ability to manage fiscal accounts. This incompatibility has been enunciated in different ways in the literature.

According to Pisani-Ferry (2012), in the Eurozone the absence of co-responsibility over public debt, the strict no-monetary financing rule and the national character of banking systems cannot contemporaneously exist. Since single countries have to autonomously manage their public debt without being able to count on the monetary financing of the central bank, during declining macroeconomic conditions they face the risk of insolvency. This in turn reduces the capital inflows and increases financial instability. Obstfeld (2013) describes the trilemma dimensions as those related to the single countries' inability to finance countercyclical fiscal policies in presence of macroeconomic downturns and at the same time have financial integration and financial stability. The reduced willingness of foreign capital to finance additional public expenditure increases interest rates and forces governments to implement fiscal retrenchments to restore market confidence.

We use these theoretical intuitions in this study and we show, through empirical estimates, the existence of a new policy trade-off for the Eurozone member countries. It implies that Eurozone countries cannot fully achieve free capital mobility, financial stability and fiscal policy flexibility at the same time.

The monetary union trilemma is illustrated by an equilateral triangle as in Fig. 1. The three corners represent financial stability, free capital mobility, and fiscal policy flexibility, respectively.

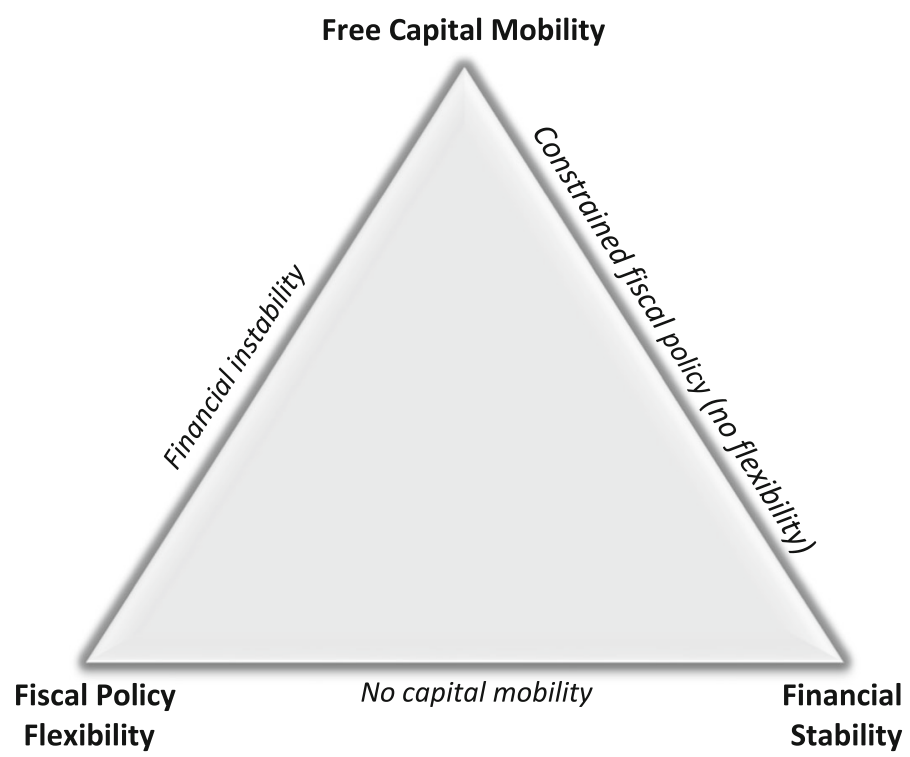

Fig. 1 The Trilemma Triangle 
According to the theorized trade-off, it is not possible to fully achieve the three policy objectives, but it is possible to achieve two of them by standing on one of the sides of the triangle (that is equivalent to standing in two corners of the triangle).

As only two-out of three-policy goals can be achieved to their full extent, we observe three distinctive extreme policy combinations (trilemma configurations): (1) fully open financial markets and full fiscal policy flexibility (implying no financial stability); (2) fully stable financial markets and full fiscal policy flexibility (with authorities forced to impose capital controls); (3) fully stable and open financial markets (thereby forcing the authorities to give up full fiscal policy flexibility). It is worth noting that the possible trilemma configurations imply also combinations in which each policy goal is neither fully achieved nor totally dropped.

The empirical evidence of the existence of such a policy trilemma can provide a new perspective in order to examine national macroeconomic policies choices in the EMU, as well as to suggest possible beneficial reforms.

\section{The trilemma indicators}

The first step in order to capture the trade-off between the policy variables involved in the trilemma requires the selection of an appropriate set of indexes. According to Fig. 1, we evaluate the EMU trilemma trough: (1) a free capital mobility index (FCM); (2) a financial stability index (FS); and (3) a fiscal policy flexibility index (FPF).

We construct the three indexes so that each of them falls between 0 and 1 . The indexes are constructed in the way that the value of 1 represents the maximum level of financial stability, a perfect degree of capital market openness, and the highest level of fiscal policy flexibility. The opposite is when the indexes assume the value of 0 .

\subsection{Free capital mobility index (FCM)}

In constructing the FCM index our focus is on financial account openness.

Among quantity-based measures, the index proposed by Lane and Milesi-Ferretti (2003) is probably the most extensively used de facto measure of a country's exposure to international financial markets. It is calculated as a country's aggregate financial assets plus liabilities relative to its gross domestic product. Our measure of capital mobility, a de facto degree of financial openness measured by total capital flows, is the ratio of gross stocks of foreign assets plus liabilities relative to GDP, similar as in Lane and Milesi-Ferretti (2006). Our indicator relies on the Balance of Payment database published by the International Monetary Fund, based on the BPM6 classification.

The index is calculated as follows: 


$$
F C M_{i, t}=\frac{(F A+F L)_{i, t}-(F A+F L)_{\min }}{(F A+F L)_{\max }-(F A+F L)_{\min }}
$$

where FA and FL are financial assets and liabilities divided by the GDP. In particular, they include: direct investments, portfolio investments, other investments and reserves. ${ }^{1}$

Hence, the FCM index describes the financial account openness and it is based on the sum in absolute values of capital flows. According to Eq. (1), the FCM index for country $i$ at time $t$ is normalized between 0 and 1 by using the maximum and minimum values in the entire panel. Therefore, perfectly open financial markets are represented by a value of 1 in the FCM index. ${ }^{2}$ Given that all the indicators adopted in this section are normalized in the same way as the FCM index (1), it is worth noting that their values should be interpreted as relative and not absolute.

\subsection{Financial stability index (FS)}

Financial stability is difficult to define and even more difficult to measure. Strictly speaking, a financial system can be characterized as stable in the absence of excessive volatility, stress or crises.

Financial stability has again shifted into the center of attention, especially since the beginning of the recent global financial crisis. To be able to detect potential pressures on financial stability and take appropriate macro prudential measures early on, economists and policymakers need to monitor and assess the degree of financial stability. From the recent financial crisis we know that there is a very broad range of indicators that must be monitored to assess overall financial stability in a reliable manner. This is because globalization, financial innovation and technological progress have accelerated many financial processes and have generated new and more complicated transmission channels. Country specific financial stability indexes have been constructed e.g. by Sales et al. (2012), by Brave and Butters (2011) or by Illing and Liu (2003). Nelson and Perli (2005) and Geršl and Hermanek (2008) discuss the methodology of selected financial soundness and financial stability indicators. Among the commonly used quantitative methods for financial stability assessment, we consider an aggregate financial stability index based on the financial instability indicator proposed by Jakubík and Slačík (2013).

We first compute a measure of overall financial instability by considering interbank, stock and government bond markets as indicated in Table 1.

Then, our overall financial stability index is constructed as:

$$
F S_{i, t}=1-\frac{F I_{i, t}-F I_{\min }}{F I_{\max }-F I_{\min }}
$$

Therefore, we have normalized the indicator of financial instability in country $i$ at time $t\left(F I_{i, t}\right)$ between 0 and 1 and then the relative normalized financial stability

\footnotetext{
${ }^{1}$ See IMF (2009) for a precise description of each aggregate.

${ }^{2}$ In the normalization of the indexes, possible outliers have been treated by winsorization at $90 \%$ (see Tukey 1962).
} 
Table 1 Financial instability index (FI)

\begin{tabular}{llll}
\hline Market & Weight & Sub-index & Sub-weight \\
\hline Money market ${ }^{\mathrm{a}}$ & \multirow{2}{*}{$1 / 3$} & Money market volatility & $1 / 2$ \\
& & Money market year-on-year change & $1 / 2$ \\
Equity market & \multirow{2}{*}{$1 / 3$} & Stock index volatility & $1 / 2$ \\
& \multirow{2}{*}{$1 / 3$} & Stock index year-on-year change & $1 / 2$ \\
Bond market & & 10-year government bond volatility & $1 / 2$ \\
& & 10-year government bond year-on-year change & $1 / 2$ \\
\hline
\end{tabular}

${ }^{\mathrm{a}}$ Based on three-month interbank offered rates

index $\left(F S_{i, t}\right)$ is calculated according to Eq. (2). From this equation, it is clear that complete financial stability is represented by a value of 1 in the index.

Quarterly interbank rates are from the OECD database, while quarterly 10-year bond yields data are from the IMF database. Stock market indexes are ibex35 (Spain), dax (Germany), mib storico (Italy), cac40 (France), athex composite (Greece), bel20 (Belgium), atx (Austria), aex (Netherlands), psi20 (Portugal), iseq overall (Ireland) and hexpic (Finland). These series have been obtained from individual indexes and national stock exchange websites at daily frequency and then converted into quarterly averages.

\subsection{Fiscal policy flexibility index (FPF)}

In general, fiscal and monetary policies are linked through the government's budget constraint. A combination of taxes, new debt issue, and seigniorage revenues must finance governments' expenditures in every period. In terms of the intertemporal budget constraint, outstanding debt must be backed by a combination of the present discounted value of current and future primary surpluses and seigniorage revenues. Nevertheless, given the impossibility for the ECB to finance national budget deficits, taxes and new debt issue are the only way by which national governments of the Eurozone can finance their deficits.

In the Eurozone, the responsibility for fiscal policy is left to national governments, but rules (SGP and Fiscal Compact) have been imposed in order to limit the flexibility of national fiscal manoeuvers. We assume that the conduct of fiscal policy by a single member of the EMU should be considered as flexible when it is able to be independent from the other member countries. In this sense, we consider fiscal flexibility as a synonym for fiscal independence from the other members' fiscal stance. In contrast, the SGP imposes that member countries' fiscal policies should be synchronized regardless of the national business cycles. Therefore, the extent of national fiscal flexibility in country $i$ at time $t$ is measured as the deviation of the national primary deficit $\left(d e f_{i, t}\right)$ from the average primary deficit in the rest of the EMU countries in the dataset $\left(\operatorname{def}_{e m u, t}\right)$. Both $\operatorname{def}_{i, t}$ and defemu,t are considered as a percentage of GDP.

It is worth noting that the deviations between the fiscal stances in different countries may be strongly influenced by the business cycle. We addressed this issue 
by regressing the primary deficit on GDP for each country and then by using the residuals as a measure of the fiscal policy $\left(d e f_{i, t}\right)$ in each member state.

Therefore, our indicator of fiscal policy flexibility is calculated as:

$$
F P F_{i, t}=\frac{\Delta d e f_{i, t}-\Delta d e f_{\text {min }}}{\Delta d e f_{\max }-\Delta d e f_{\text {min }}}
$$

where $\Delta d e f_{i, t}=\left|d e f_{i, t}-d e f_{e m u, t}\right|$. Also this index lies between 0 and 1 with a higher value indicating greater degree of fiscal independence. In this case, data are obtained from the Oxford Economics database.

\subsection{Tracking the trilemma indexes}

In our study, we focus on 11 countries of the EMU (Austria, Belgium, Finland, France, Greece, Germany, Ireland, Italy, Netherlands, Portugal and Spain) and adopt quarterly data spanning the period $1999 q 1-2012 q 4$.

Before performing the empirical analysis and verify the existence of the trilemma, we briefly summarize our data in order to evaluate how the constructed indexes vary across time and countries.

First, we use the radar charts in order to show the panel average values of the three indicators in the entire period covered by the dataset (Fig. 2, panel A) and in three sub-periods (Fig. 2, panel B). In the radar charts the origin represents zero capital flows, no fiscal policy flexibility and maximum financial instability. Figure 2, panel A, shows that financial stability has a higher average value $(0.58)$ when compared to fiscal independence $(0.32)$ and free capital mobility $(0.35)$. Then, from the entire panel perspective it can be concluded that safeguarding financial stability has been prioritized and that EMU countries have substantially retained fiscal independence. However, Fig. 2 panel B shows how the link between the three indexes has varied over time. We can observe how the financial stability indicator slightly increases in the first two sub-periods going from 0.63 to 0.72 , but then
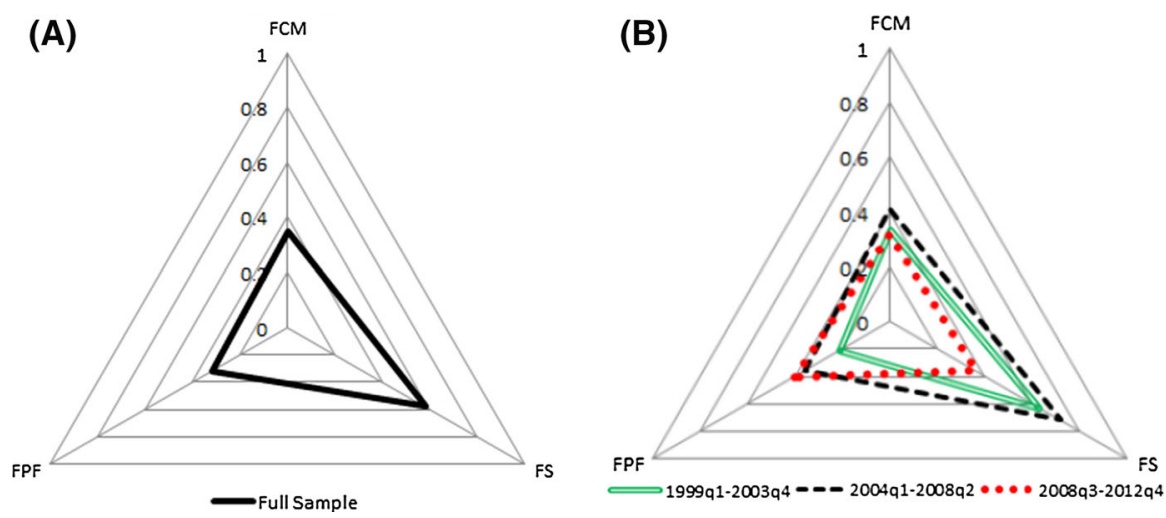

Fig. 2 The trilemma indexes in the panel and time dimensions 
sharply declines with an average value of 0.37 after 2008 . This result should not be surprising as the latter is exactly the period of the global financial crisis. Remarkably, in the same time-span, fiscal flexibility augments from 0.22 to 0.40 on average. This can be interpreted as the result of the asymmetric effects of the financial crisis in Europe. Following the asymmetric impact of the financial shocks, some member countries of the EMU have reacted by implementing fiscal policies not in line with the ones in the rest of the EMU. Such divergence between different national fiscal policies is the main reason behind the increase in our index of fiscal flexibility. Hence, this descriptive analysis suggests that financial instability has affected fiscal policy decisions.

Furthermore, from this descriptive analysis, it seems that the increase in one indicator has implied a reduction in another one. Table 2 reports the value from Fig. 2 panel A together with standard deviations. Furthermore, the table reports the country and quarter in which the panel maximum and minimum for each index are observed. Noticeably, the minimum value for financial stability is scored by Greece, while the maximum fiscal flexibility by Ireland and both fall in the period of the crisis.

Finally, in Table 2 we also show for which countries and in which periods the normalized and winsorized indicators are for at least 1 year at their maximum or minimum values. Again, this shows how severe and prolonged financial instability has occurred in Greece and Portugal during the financial crisis, while strong fiscal independence has been evidenced for Spain and Ireland during the crisis.

Table 2 Summary of the trilemma indexes

\begin{tabular}{llll}
\hline & FS & FPF & FCM \\
\hline Mean & 0.58 & 0.32 & 0.35 \\
SD & 0.27 & 0.27 & 0.28 \\
Max & Italy-2004q3 & Ireland-2010q2 & Belgium-2008q4 \\
Min & Greece-2012q4 & Belgium-2002q1 & France-2012q4 \\
Max & France 2004q3-2005q2 & Ireland 2004q2-2007q2 & Netherlands 2005q1-2006q1 \\
$(1$ year) & Portugal 2004q3-2005q4 & Ireland 2009q4-2011q1 & Austria 2005q1-2005q4 \\
& & Spain 2011q2-2012q4 & Belgium 2007q4-2008q4 \\
Min & Greece 2010q2-2012q4 & France-1999q1-1999q4 & Germany 2001q2-2002q1 \\
$(1$ year) & Portugal 2011q2-2012q4 & Netherlands-2012q1-2012q4 & \\
& Greece 1999q1-2000q1 & & \\
\hline
\end{tabular}

Max and Min refer to the panel maximum and minimum values of the indexes

Max (1 year) refers to periods of at least 1 year in which the index has scored its maximum after winsorization

Min (1 year) refers to periods of at least 1 year in which the index has scored its minimum after winsorization 


\section{Empirical analysis and results}

The existence of policy alternatives inside the traditional Mundell-Fleming trilemma was first estimated by Aizenman et al. (2008) and then applied in other studies (see for instance Hutchison et al. 2012; Aizenman et al. 2015; Aizenman and Ito 2014).

In this section, we empirically investigate the existence of the monetary union trilemma for the EMU countries in our sample considered both as a whole union and individually.

To show that countries in the EMU have faced the monetary union impossible trinity, it has to be demonstrated that there is a trade-off between the policy goals of national fiscal policy flexibility, financial stability and free capital flows and that policy makers have to define a weighted average combining the three goals.

The simplest way to test the existence of the trilemma is to suppose a linear relation. Following Aizenman et al. (2008, 2013), a linear trilemma can be estimated by testing that the weighted sum of the three policy variables adds up to a constant. If this is verified, it implies that, in the case of the monetary union trilemma, higher financial stability should linearly induce lower capital mobility or lower fiscal flexibility, or a combination of these two policy adjustments. In particular, this implies to examine the goodness of fit of the following linear regression:

$$
1=\alpha_{1} F P F_{i, t}+\alpha_{2} F S_{i, t}+\alpha_{3} F C M_{i, t}+\varepsilon_{i, t}
$$

according to which the weighted sum of the indexes of Eqs. (1), (2) and (3) adds up to $1 .^{3}$ If we find that the goodness of fit of Eq. (4) is high, it would suggest that the trade-off is binding and that the specification is rich enough to explain it. Therefore, the higher the goodness of fit of the estimated model the stronger the support for the existence of the trilemma.

An alternative specification is a logarithmic one (see Hsing 2012):

$$
1=\beta_{1} \ln F P F_{i, t}+\beta_{2} \ln F S_{i, t}+\beta_{3} \ln F C M_{i, t}+\mu_{i, t}
$$

where in order to avoid zero values, a value of 1 is added to each indicator before taking its logarithm.

As a first step of our analysis, we compare the outcomes of the linear estimation of Eq. (4) with the results obtained by the linear-logarithmic specification (5). Table 3 (panel A) reports the results of the estimations of Eqs. (4) and (5).

The two regressions provide similar estimated coefficients that are all statistically significant at $1 \%$. Then, in order to choose one of the two non-nested models, we first compare them by means of the Davidson and MacKinnon (1981) procedure. The F-test connected with this method suggests that neither of the models has to be rejected (see Table 3, panel $\mathrm{B}$ ).

Therefore, we compare the two models on the basis of their estimated errors (via the Box-Cox procedure), AIC and $\mathrm{R}^{2}$, respectively. The results reported in Table 3 ,

\footnotetext{
${ }^{3}$ Geometrically, the trilemma constraint given by Eq. (4) represents the sum of the perpendicular distances from a generic point in the triangle to its sides. This is valid for any point and the sum of such distances is always a constant equal to the altitude of the triangle (Viviani's theorem), that in our case is equal to 1 .
} 


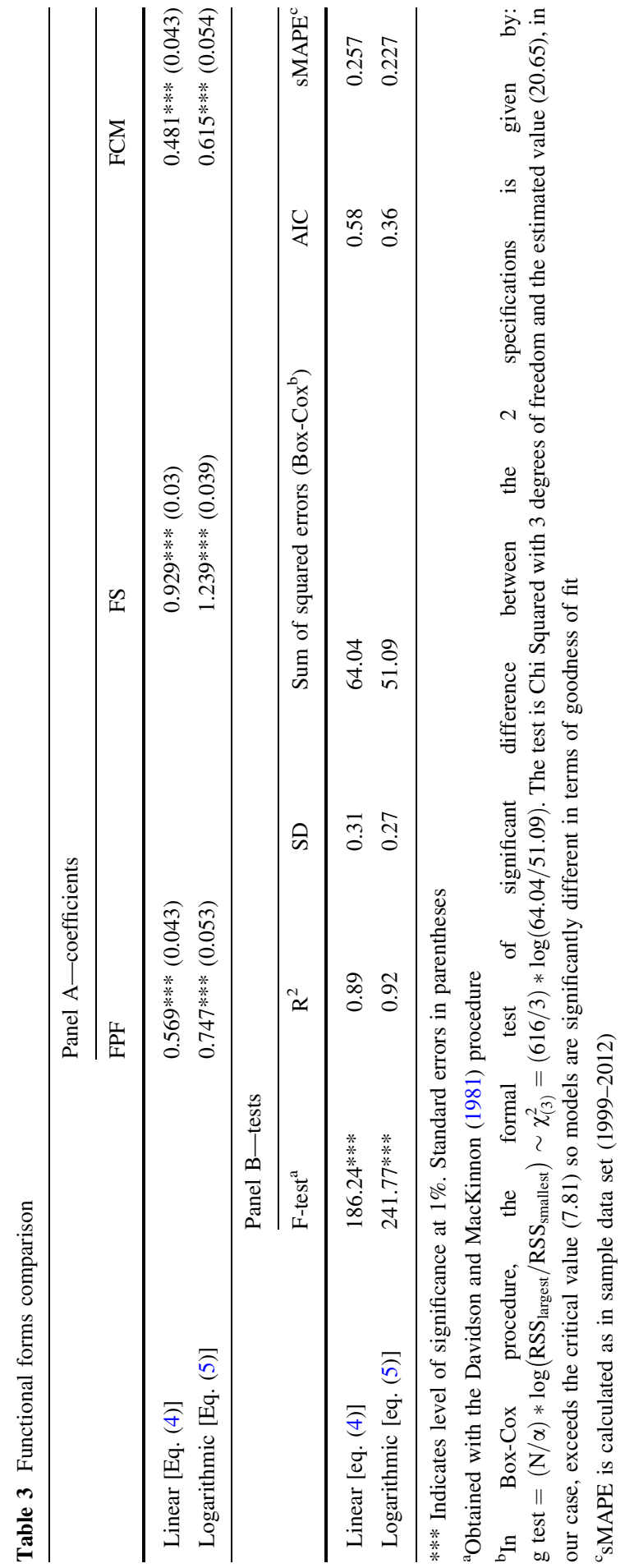


Table 4 Panel estimation of the trilemma

\begin{tabular}{llll}
\hline & Estimated coefficient & Sample mean & Contribution (weight) \\
\hline FPF & $0.747^{* * *}(0.053)$ & 0.259 & 0.19 \\
FS & $1.239^{* * *}(0.039)$ & 0.443 & 0.55 \\
FCM & $0.615^{* * *}(0.054)$ & 0.283 & 0.17 \\
\hline
\end{tabular}

Sum of contributions $\left(\mathrm{R}^{2}\right)=0.91$

*** Indicates level of significance at $1 \%$. Standard errors in parentheses

panel B, suggest that the logarithmic regression has the lowest values of the errors standard deviation, mean absolute percent error, sum of squared errors, and Akaike information criterion. Moreover, it also shows a higher $\mathrm{R}^{2}$.

Therefore, we decide to conduct our analysis on the basis of Eq. (5); it is first estimated for the entire panel and full sample period. In the case of a high goodness of fit of this regression and positive estimated coefficients, it can be concluded that Eq. (5) is able to model the trade-off between the three policy variables. Conversely, a low goodness of fit and/or negative estimated coefficients would indicate that the theory behind the trilemma is not correct, or that the relationship between its variables cannot be represented with the adopted functional form.

The relevant results from the panel estimation of Eq. (5) are summarized in Table 4. As already shown in Table 3, all the three variables are highly statistically significant, the estimated coefficients have positive sign and the general fit is good. All these elements suggest that the existence of the monetary union policy trilemma cannot be rejected. ${ }^{4}$ Therefore, this constitutes evidence that the member countries of the EMU face an impossible trinity between free capital mobility, financial stability and flexible national fiscal policies.

It is worth noting that the estimated coefficients do not provide accurate measure of the weights that each policy goal has in the trilemma. However, it is crucial to know these weights in order to quantify the trilemma configuration.

In order to obtain these weights, we have to multiply the estimated coefficients by the actual values of the variables. Hence, we calculate the weights characterizing the trilemma configuration for fiscal policy flexibility, financial stability and free capital mobility as $\hat{\beta}_{1} * \overline{\ln F P F}, \hat{\beta}_{2} * \overline{\ln F S}$ and $\hat{\beta}_{3} * \overline{\ln F C M}$, respectively. Where $\overline{\operatorname{lnFPF}}, \overline{\ln F S}$ and $\overline{\operatorname{lnFCM}}$ are the panel sample means of each variable reported in the third column of Table 4 , while $\hat{\beta}_{1}, \hat{\beta}_{2}$ and $\hat{\beta}_{3}$ are the estimated coefficients from Eq. (5). Thus, in the fourth column of Table 4 we report the calculated contribution of each policy goal to the trilemma configuration. If the approximation is satisfactory, the sum of these weights should be close to 1 . Then, in the note of Table 4 we also report the $\mathrm{R}^{2}$, that must coincide with the sum of the three calculated weights and therefore measures the relevance of the trilemma according to the data. This makes it clear why higher levels of the $\mathrm{R}^{2}$ imply stronger evidence for the existence of the trilemma. In our estimation, its high value supports the existence of the trade-off.

\footnotetext{
${ }^{4}$ On the contrary, estimated negative coefficients, or a low $\mathrm{R}^{2}$, would have suggested that the hypothesized trade-off is not binding, or that the specification adopted is not appropriate.
} 
Table 5 Panel Estimations in Different Time Periods

\begin{tabular}{llll}
\hline & Estimated coefficient & Sample mean & Contribution (weight) \\
\hline 1999q1-2003q4 & & & \\
FPF & $0.958^{* * *}(0.112)$ & 0.186 & 0.18 \\
FS & $1.318^{* * *}(0.057)$ & 0.478 & 0.63 \\
FCM & $0.479^{* * *}(0.087)$ & 0.269 & 0.13 \\
2004q1-2008q2 & & & \\
FPF & $0.322^{* * *}(0.063)$ & 0.289 & 0.09 \\
FS & $1.365^{* * *}(0.046)$ & 0.536 & 0.73 \\
FCM & $0.424 * * *(0.063)$ & 0.319 & 0.14 \\
2008q3-2012q4 & & & 0.27 \\
FPF & $0.878^{* * *}(0.094)$ & 0.312 & 0.39 \\
FS & $1.298^{* * *}(0.101)$ & 0.299 & 0.24 \\
FCM & $0.924 * * *(0.104)$ & 0.258 & \\
\hline
\end{tabular}

For the normalization of the indexes, the maximum and minimum adopted are the ones of the entire sample

Sum of contributions $\left(\mathrm{R}^{2}\right)$ are: 0.94 for $1999 \mathrm{q} 1-2003 \mathrm{q} 4 ; 0.96$ for $2004 \mathrm{q} 1-2008 \mathrm{q} 2 ; 0.90$ for 2008q3-2012q4

*** Indicates level of significance at $1 \%$. Standard errors in parentheses

Furthermore, the estimated weights assigned to each policy goal show that the main focus has been on financial stability, that has a weight of 0.55 , while the estimated contributions to the trade-off of fiscal policy flexibility and free capital mobility are 0.19 and 0.17 , respectively. Therefore, our results suggest that the trilemma is binding in the Eurozone, and that the main weight in its configuration has been on financial stability. This reflects the general trend in the EMU, where national fiscal policies have most often been synchronized in order to fulfill the common rules and the imposed fiscal policy constraints.

Given the length of our dataset, the results obtained so far may be due to different trilemma configurations over the years in the EMU. Hence, we also perform our panel analysis for the same three sub-periods adopted in the descriptive analysis of data (1999q1-2003q4, 2004q1-2008q2 and 2008q3-2012q4). We have chosen to split the sample at 2008q3 due to the beginning of the financial crisis. This intuition has also been confirmed by a Chow stability test showing that there is a structural break at that point. ${ }^{5}$ Moreover, we have divided the sample in three sub-periods, adopting $2004 \mathrm{q} 1$ as another threshold, in order to compare estimations covering the same number of years.

Thus, thanks to this analysis, we are able to separately cover the period of the financial crisis and compare its trilemma configuration with the ones characterizing the beginning of the EMU experience and following years. The results are reported in Table 5. The three sub-periods estimations confirm the result that the trilemma is binding.

\footnotetext{
5 Results of the structural break analysis are available upon request.
} 
It is clear that the trilemma configuration has been similar in the first two subperiods, with strong emphasis on financial stability and low weight assigned to fiscal flexibility.

The latter can be interpreted as a general evidence of both fiscal discipline and co-movements in the EMU in order to safeguard financial stability.

Noticeably, the degree of fiscal flexibility is very low in the period 2004q1-2008q2 and this can be considered as evidence of the fact that the crisis was not linked to previous fiscal policy decisions and that, on the contrary, fiscal policies were similar across different member countries in the pre-crisis period.

Then, starting from the financial crisis, in the period 2008q3-2012q4, the trilemma configuration shows some changes as the weight of financial stability is reduced from 0.73 to 0.39 and the weight of fiscal flexibility increases from 0.09 to 0.27. This can be interpreted as the consequence of the increase in financial instability characterizing the period of the crisis that has forced some of the member countries to modify their fiscal stance more than in the rest of the union. The asymmetric impact of the financial shocks has then forced some member countries to react by performing fiscal manoeuvers not in line with the ones of the rest of the EMU. As a result, our fiscal policy flexibility indicator has increased given the fact that similarities in national fiscal stances have declined. This change in the degree of fiscal flexibility has then modified the trilemma configuration. ${ }^{6}$

Another relevant element connected with our analysis is that estimating the existence of the trilemma by using a pooled panel estimation method may be misleading because an increase in one of the indexes for one member country may involve a fall in the weighted sum of the other two indexes in another country, but a pooled estimation may still interpret this as a relation between the three indexes for each country (see Aizenman et al. 2013). Therefore, in order to validate our findings, we also test the relation between the trilemma variables for each country separately. ${ }^{7}$ The estimated trilemma configurations are reported, both graphically and numerically, in Fig. 3.

First, according to our estimations, the validity of the monetary union trilemma can be confidently confirmed also from the perspective of single countries estimations as all the estimated coefficients are positive and the $\mathrm{R}^{2}$ is consistently high across countries. The results concerning the configuration of the trade-off also show that financial stability receives high weight in the trilemma in the large majority of countries. Therefore, the general result from the panel analysis is confirmed.

Nevertheless, Fig. 3 highlights some relevant differences between countries. Firstly, Greece, Ireland and Portugal show substantially lower weights of financial stability when compared with the rest of the union. At the same time, Greece seems to have combined this lower weight on financial stability with more flexible fiscal policies.

\footnotetext{
${ }^{6}$ One can argue that also the tightening of the institutional restrictions on deficits should have impacted the degree of fiscal flexibility in Europe. However, these reforms have started only after 2010 and their impact is not represented in our data set.

7 In this case, the weights of the variables in the trilemma configuration are calculated by multiplying the coefficients estimated with single countries regression by the country mean of each variable.
} 


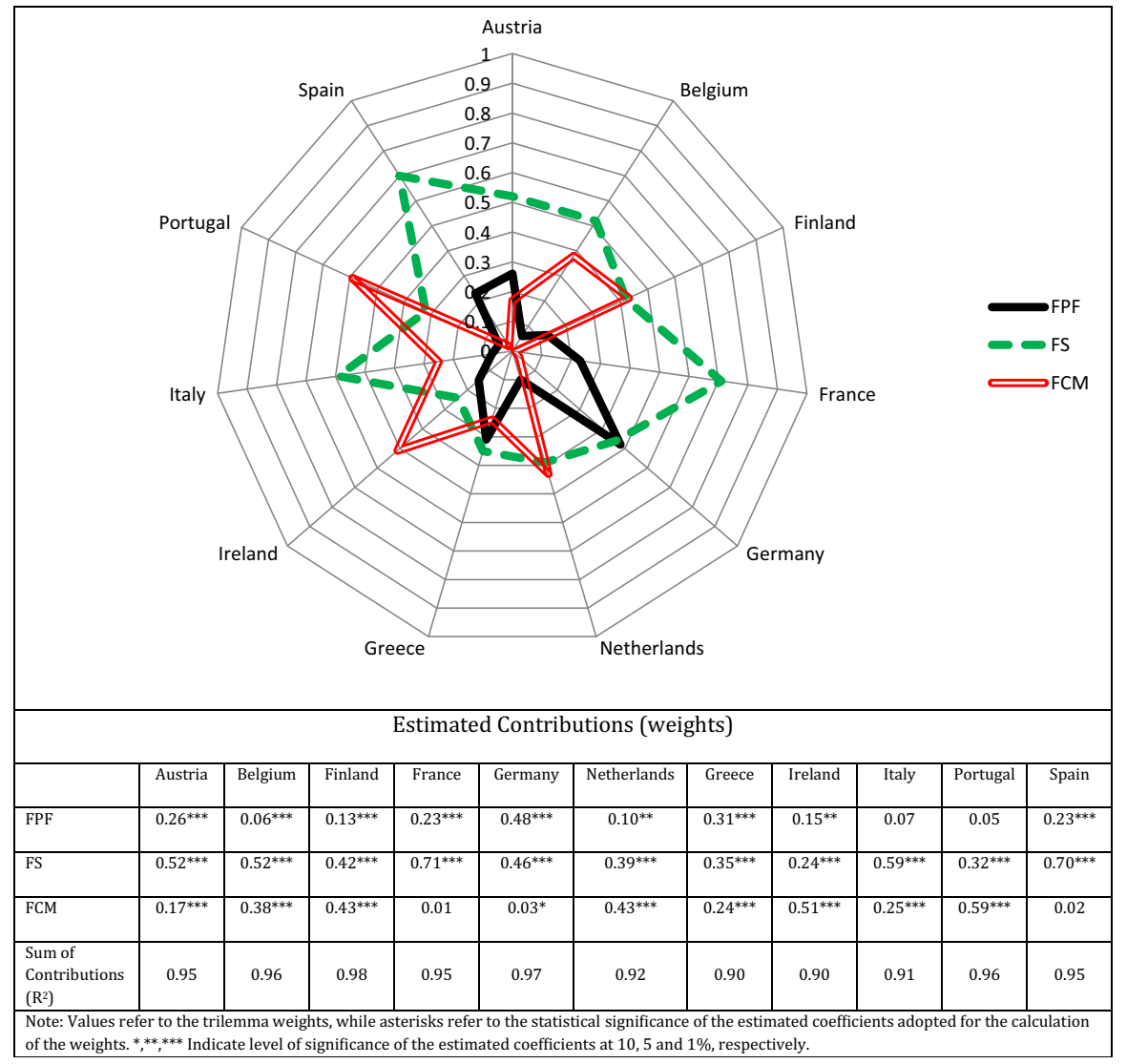

Fig. 3 Trilemma configurations in single member countries

Figure 3 also shows how the lowest weights for fiscal flexibility are estimated in the case of Portugal, Italy, Netherlands and Belgium.

The differences between countries highlighted in Fig. 3 suggest the necessity of additional work strictly focusing on a cross-section analysis of the trilemma configurations and linking these to the economic and institutional characteristics of each country. However, this goes beyond the scope of the present paper.

\section{Robustness analysis}

In this section, we present the outcomes of several alternative estimations in order to test the robustness of our results and provide some additional insights. We focus on three aspects related to our estimations: (1) we investigate if our results depend on the estimation method adopted; (2) as the employed indicators have some elements of arbitrariness, we consider alternative definitions of such variables in order to test the robustness of our results; (3) in order to support the specificity of the trilemma 
Table 6 Panel estimation of the trilemma controlling for estimation methods

\begin{tabular}{llll}
\hline & Estimated coefficient & Sample mean & Contribution (weight) \\
\hline \multicolumn{2}{l}{ Two-stage least squares } & & \\
FPF & $0.811^{* * *}(0.063)$ & 0.259 & 0.21 \\
FS & $1.166^{* * *}(0.063)$ & 0.443 & 0.52 \\
FCM & $0.694^{* * *}(0.042)$ & 0.283 & 0.20 \\
Kalman Filter & & & \\
FPF & $0.747^{* * *}(0.053)$ & 0.259 & 0.19 \\
FS & $1.239^{* * *}(0.039)$ & 0.443 & 0.55 \\
FCM & $0.614^{* * *}(0.054)$ & 0.283 & 0.17 \\
\hline
\end{tabular}

In the 2-SLS the variables FCM and FPF are instrumented with their lags

Sum of contributions $\left(\mathrm{R}^{2}\right)$ for the two-stage least squares estimation $=0.93$

Sum of contributions $\left(\mathrm{R}^{2}\right)$ for the Kalman filter estimation $=0.91$

*** Indicates level of significance at $1 \%$. Standard errors in parentheses

for countries in the EMU, we also verify that the trade-off implied by the trilemma is not binding for a different group of countries outside the EMU.

\subsection{Alternative estimation methods}

As already highlighted in Sect. 4, specification errors and methods of estimation may affect the results obtained concerning the trilemma configuration. Besides the alternative between a linear and a logarithmic specification, other possible estimations considered in the literature imply estimating a trilemma equation via two-stage least squares, Kalman filter and tobit (see for instance Ito and Kawai 2014; Cortuk and Singh 2013). Therefore, we re-estimate Eq. (5) by means of two alternative methods: (1) the two stage least squares and (2) the Kalman filter.

Trilemma estimations force the number of explanatory variables to be three and are then prone to endogeneity problems due to omitted variables. Moreover, in our case measurement errors can characterize for instance the fiscal policy variable because quarterly data on fiscal policies are based on cash data and estimations. Therefore, following the standard approach in dealing with endogeneity, we estimate Eq. (5) using instrumental variables regression. In the two-stage least squares estimation we use lagged observations for the free capital mobility and fiscal policy flexibility indexes as instruments. ${ }^{8}$ The results reported in Table 6 highlight the fact that this estimation basically confirms the initial results obtained from the estimation of Eq. (5), both in terms of goodness of fit and trilemma configuration.

Another possibility implies employing the Kalman filter technique in the context of the trilemma regression by allowing its coefficients to vary over time. In order to

\footnotetext{
${ }^{8}$ We have also estimated Eq. (5) by using lagged variables of all the three indexes as instruments and the results obtained are similar to the ones reported in Table 6.
} 
employ the Kalman filter, we have to represent our trilemma equation in state-space form. This requires a measurement equation:

$$
1=\beta_{1, t} \ln F P F_{i, t}+\beta_{2, t} \ln F S_{i, t}+\beta_{3, t} \ln F C M_{i, t}+\eta_{i, t}
$$

and three transition equations:

$$
\beta_{1, t}=\rho_{1} \beta_{1, t-1}+\gamma_{t} ; \beta_{2, t}=\rho_{2} \beta_{2, t-1}+v_{t} ; \beta_{3, t}=\rho_{3} \beta_{3, t-1}+\delta_{t}
$$

where $\eta_{i, t}, \gamma_{t}, v_{t}$, and $\delta_{t}$ are assumed to be normally distributed with zero mean. The measurement equation is our main trilemma regression, while according to the transition equations we treat the parameters of the trilemma indexes as unobserved and allow them to vary over time as $\mathrm{AR}(1)$ processes. As shown in Table 6, also the Kalman filter results are almost identical to the ones presented in Table 4.

Another part of our estimation that requires further investigation is the subperiods analysis summarized in Table 5. This is due to the fact that the limited number of observations involved in each sub-period may have affected the estimation results and their reliability. Hence, we use dummies for the subsamples interacted with all variables and run one regression with interactions instead of 3 separate regressions. This methodology considers the use of interaction dummy variables and it allows the coefficients of the relationship between the dependent variable and the independent variables to be different depending on whether the condition specified by a dummy variable is met. In our case, these conditions are related to the three different sub-periods (1999q1-2003q4, 2004q1-2008q2 and 2008q3-2012q4) and the dummies are D1, D2 and D3 like in the following regression:

$$
\begin{aligned}
1= & \beta_{1} D 1 \ln F P F_{i, t}+\beta_{2} D 1 \ln F S_{i, t}+\beta_{3} D 1 \ln F C M_{i, t}+\beta_{4} D 2 \ln F P F_{i, t} \\
& +\beta_{5} D 2 \ln F S_{i, t}+\beta_{6} D 2 \ln F C M_{i, t}+\beta_{7} D 3 \ln F P F_{i, t} \\
& +\beta_{8} D 3 \ln F S_{i, t}+\beta_{9} D 3 \ln F C M_{i, t}+\mu_{i, t}
\end{aligned}
$$

We report the estimation results from Eq. (8) in Table 7. Again, the results in Table 7 match the ones reported in Table 5 as also by using Eq. (8) we can conclude that the trilemma configuration has been constant during the first two subperiods and that strong emphasis on financial stability and low weight to fiscal flexibility have characterized the trilemma configuration in these two periods. Furthermore, the degree of fiscal flexibility has been low in the period 2004q1$2008 \mathrm{q} 2$ and this confirms our results showing that the crisis was not linked to previous fiscal policy decisions. The dummy variables estimation also confirms that, starting from the financial crisis, the trilemma configuration has changed as the weight of financial stability has reduced and the weight of fiscal flexibility has increased.

Thus, from the analyses conducted in this section we can conclude that our main results can be considered as not depending on the estimation method adopted. 
Table 7 Panel estimations of different time periods with dummy variables

\begin{tabular}{llll}
\hline & Estimated coefficient & Sample mean & Contribution (weight) \\
\hline 1999q1-2003q4 & & & 0.20 \\
FPF & $1.068 * * *(0.118)$ & 0.186 & 0.62 \\
FS & $1.297 * * *(0.059)$ & 0.478 & 0.13 \\
FCM & $0.488^{* * *}(0.089)$ & 0.269 & \\
$2004 q 1-2008 \mathrm{q} 2$ & & & 0.09 \\
FPF & $0.304 * * *(0.079)$ & 0.289 & 0.74 \\
FS & $1.38 * * *(0.057)$ & 0.536 & 0.13 \\
FCM & $0.409 * * *(0.079)$ & 0.319 & 0.27 \\
$2008 \mathrm{q} 3-2012 \mathrm{q} 4$ & & & 0.39 \\
FPF & $0.878 * * *(0.076)$ & 0.312 & 0.24 \\
FS & $1.298 * * *(0.081)$ & 0.299 & 0.258 \\
FCM & $0.924 * * *(0.084)$ & & \\
\hline
\end{tabular}

Sum of contributions $\left(\mathrm{R}^{2}\right)$ are: 0.95 for 1999q1-2003q4; 0.96 for $2004 \mathrm{q} 1-2008 \mathrm{q} 2 ; 0.90$ for 2008q3-2012q4

*** Indicates level of significance at $1 \%$. Standard errors in parentheses

\subsection{Alternative indicators}

In this section we re-estimate Eq. (5) by employing alternative measures of the trilemma indicators. Specifically, we employ two alternative indicators measuring financial stability, two further indicators for fiscal policy flexibility and one additional indicator for free capital mobility.

\subsubsection{Alternative financial stability indicators}

Concerning the financial stability indicator, we adopt two additional measures to verify the robustness of our results. First, we employ a narrower version of our indicator focusing on the government bond market that is calculated as:

$$
F S_{i, t}^{1}=1-\frac{F I_{i, t}^{1}-F I_{\text {min }}^{1}}{F I_{\text {max }}^{1}-F I_{\text {min }}^{1}}
$$

where $F I_{i, t}^{1}$ is the instability on the government bond market for country $i$ at time $t$ calculated as in Table 1 . Thus, $F I_{i, t}^{1}$ is the average between the volatility and the year-on-year change of the 10-year government bond yields. Then, the alternative indicator measuring financial stability is constructed according to Eq. (9). The results are reported in Table 8, panel A, and confirm the existence of the trilemma.

The trilemma configuration in this case shows a slightly higher weight for financial stability reflecting the stronger link between fiscal policy decisions and the variations of the bond yields.

As the two financial stability indexes employed so far rely on the same logic for their calculation, we also estimate the trilemma indicator by employing a different 
Table 8 Panel estimation of the trilemma controlling for different financial stability indexes

\begin{tabular}{llll}
\hline & Estimated coefficient & Sample mean & Contribution (weight) \\
\hline Panel A & & & \\
FPF & $0.381^{* * *}(0.053)$ & 0.259 & 0.10 \\
FS $^{1}$ & $1.335^{* * *}(0.036)$ & 0.504 & 0.67 \\
FCM & $0.568^{* * *}(0.049)$ & 0.283 & 0.16 \\
Panel B & & & \\
FPF & $0.66^{* * *}(0.532)$ & 0.259 & 0.17 \\
FS $^{2}$ & $1.189^{* * *}(0.036)$ & 0.489 & 0.58 \\
FCM & $0.593^{* * *}(0.053)$ & 0.283 & 0.17 \\
\hline
\end{tabular}

Sum of contributions $\left(\mathrm{R}^{2}\right)$ with $\mathrm{FS}^{1}=0.93$

Sum of contributions $\left(\mathrm{R}^{2}\right)$ with $\mathrm{FS}^{2}=0.92$

*** Indicates level of significance at $1 \%$. Standard errors in parentheses

measure based on the financial stress index, FSI, developed and made available by Duprey et al. (2015). This indicator is obtained on the basis of the stress on three financial market segments (equity, bond and foreign exchange rate) by using two variables for each segment. Stress in the equity market is captured by the monthly realized volatility (computed as the monthly average of absolute daily log-returns of the real stock price index) and by the cumulative maximum loss (the maximum loss compared to the highest level of the stock market over two years). Stress in the bond market is measured by the monthly realized volatility (computed as the monthly average of absolute daily changes in the real yield on 10-year government bonds) and by the cumulative difference (the maximum increase in basis points of the real government bond spread with respect to Germany over a two-year rolling window). Stress in the exchange rate market is measured by means of realized volatility (computed as the absolute value of the monthly growth rate of the real effective exchange rate) and by the cumulative change over six months. After harmonizing these indicators with the empirical cumulative density function (see Hollo et al. 2012), the three sub-indexes measuring the stress in each segment are obtained by averaging the two variables computed for each of them. Finally, the financial stress measure is obtained by aggregating the time-varying cross correlations of these indexes. The monthly data provided by the authors have been transformed into quarterly observations and then the financial stability indicator has been obtained as $^{9} F S_{i, t}^{2}=1-F S I_{i, t}$.

The results of the estimation are reported in Table 8, panel B and are almost identical to the results obtained with our financial stability indicator as reported in Table 4.

\footnotetext{
${ }^{9}$ Where the usual normalization and winsorization have been applied.
} 
Table 9 Panel estimation of the trilemma controlling for different fiscal policy flexibility indexes

\begin{tabular}{llll}
\hline & Estimated coefficient & Sample mean & Contribution (weight) \\
\hline Panel A & & & \\
FPF $^{1}$ & $0.774^{* * *}(0.047)$ & 0.348 & 0.27 \\
FS & $0.938^{* * *}(0.046)$ & 0.443 & 0.42 \\
FCM & $0.846^{* * *}(0.049)$ & 0.283 & 0.24 \\
Panel B & & & \\
FPF $^{2}$ & $0.824^{* * *}(0.047)$ & 0.405 & 0.33 \\
FS & $1.029^{* * *}(0.041)$ & 0.443 & 0.46 \\
FCM & $0.487^{* * *}(0.053)$ & 0.283 & 0.14 \\
\hline
\end{tabular}

Sum of contributions $\left(\mathrm{R}^{2}\right)$ with $\mathrm{FPF}^{1}=0.93$

Sum of contributions $\left(\mathrm{R}^{2}\right)$ with $\mathrm{FPF}^{2}=0.93$

*** Indicates level of significance at $1 \%$. Standard errors in parentheses

\subsubsection{Alternative fiscal flexibility indicators}

Our definition of fiscal flexibility has been identified on the possibility of central governments to pursue national economic and political objectives and deviate from the fiscal policy in the rest of the union. Clearly, this is not the only possible interpretation and many other alternatives can be considered. It can be argued that the Stability and Growth Pact does not necessarily force all member states to implement similar fiscal policies and that this depends on the general economic conditions related to the business cycles in member countries. Thus, as alternative measure of fiscal policy independence, we also present an index based on the correlation between the domestic fiscal stance and the domestic output-gap. The index is calculated as follows:

$$
F P F_{i, t}^{1}=\frac{\operatorname{corr}\left(P d e f_{i, t} ; \Delta G A P_{i, t}\right)+1}{2}
$$

where $P d e f_{i, t}$ represents the primary deficit in country $i$ at time $t$, while $\triangle G A P_{i, t}$ is obtained as the difference between the output-gap in country $i$ (obtained with the HP filter) and its average in the rest of the EMU. ${ }^{10}$ The results of the estimation with this alternative indicator are reported in Table 9, panel A, and they confirm that the highest weight in the trilemma configuration has been for financial stability over fiscal flexibility. However, in this case the difference between these two weights is slightly lower when compared to our results in Table 4.

As we understand that both fiscal policy flexibility indexes adopted may have some elements of arbitrariness, we employ a third indicator based on institutional factors. The measure adopted is the fiscal rule index, FRI, provided by the European Commission. The FRI index is constructed by first assigning a strength value to each

\footnotetext{
${ }_{10}$ Also in this case we have first regressed the primary deficit on GDP for each country and then we have used the residuals as a measure of the fiscal policy $\left(P d e f_{i, t}\right)$ in each member state.
} 
existing rule, and then by computing a weighted sum of all fiscal rule strength indexes for each member country. Assuming that a decrease in FRI (a decrease in the number and strength of fiscal rules) implies an increase in fiscal policy flexibility, we have employed this index in order to construct another measure of fiscal policy flexibility as:

$$
F P F_{i, t}^{2}=1-\frac{F R I_{i, t}-F R I_{\text {min }}}{F R I_{\text {max }}-F R I_{\text {min }}}
$$

The results of the estimation of Eq. (5), with the indicator (11) substituting (3), are reported in Table 9, panel B. Also under this specification, our estimation confirms the existence of the trilemma and the highest weight for financial stability in the trilemma configuration. As the main difference with respect to our previous results, the estimated weight of fiscal policy flexibility by means of $\mathrm{FPF}^{2}$ results to be the highest (0.33) when compared to the results in Table $4(0.19)$ and Table 9 panel A (0.27).

\subsubsection{Alternative free capital mobility indicator}

The employed capital mobility indicator is a de facto one based on the volumes of capital flows and their time variation. This implies that changes in our indicator may also be the consequence of deleveraging rather than of actual restrictions on capital mobility.

Thus, in this section we report the results of the trilemma estimation obtained by using a de jure measure of free capital mobility. To this aim, we employ the overall capital control indicator proposed by Fernández et al. (2016). This indicator considers capital controls on inflows and outflows for 10 asset categories and it is built on the data in Schindler (2009) and on the IMF's Annual Report on Exchange Arrangements and Exchange Restrictions (AREAER). The indicator ranges between 0 and 1, with 0 representing no capital restrictions. Thus, for our analysis we consider the normalized complement to 1 of the index in order to retrieve a measure of free capital mobility. As the original dataset is provided in yearly frequency, we have also transformed the series in quarterly by linear approximation.

The results of the estimation with this index are reported in Table 10 and they still support the existence of the trilemma. In this case the trilemma composition seems to change as both $\mathrm{FCM}^{1}$ and FS score a weight of 0.38 , while the weight of FPF does not significantly change (0.18). However, it seems worth noting that this

Table 10 Panel estimation of the trilemma controlling for different free capital mobility index

\begin{tabular}{llll}
\hline & Estimated coefficient & Sample mean & Contribution (weight) \\
\hline FPF & $0.693 * * *(0.046)$ & 0.259 & 0.18 \\
FS & $0.856^{* * *}(0.044)$ & 0.443 & 0.38 \\
FCM $^{1}$ & $0.725^{* * *}(0.039)$ & 0.521 & 0.38 \\
\hline
\end{tabular}

Sum of contributions $\left(\mathrm{R}^{2}\right)=0.94$

*** Indicates level of significance at $1 \%$. Standard errors in parentheses 
Table 11 Specificity of the trilemma (panel)

\begin{tabular}{llll}
\hline & Stand-alone countries & EMU-core & EMU-periphery \\
\hline FPF & $0.152^{* * *}(0.029)$ & $0.931^{* * *}(0.074)$ & $0.372^{* * *}(0.094)$ \\
FS & $1.517^{* * *}(0.009)$ & $1.296^{* * *}(0.052)$ & $1.129^{* * *}(0.067)$ \\
FCM & $0.034(0.024)$ & $0.489^{* * *}(0.058)$ & $1.132^{* * *}(0.123)$ \\
\hline
\end{tabular}

Stand-alone countries: Australia, Japan, Russia, USA, UK

EMU-core: Austria, Belgium, Finland, France, Germany, Netherlands

EMU-periphery: Greece, Ireland, Italy, Portugal, Spain

Estimations cover the period 2000q2-2012q4 for each group of countries

$* * *$ Indicates level of significance at $1 \%$, no asterisk indicates no significance at $10 \%$. Standard errors in parentheses

result may have been determined also by the limited time variation of the de jure index and by the fact that $31 \%$ of the observations in our panel are equal to 1 for $\mathrm{FCM}^{1}$. The latter is also reflected in the high sample mean of $\mathrm{FCM}^{1}$.

\subsection{Specificity of the trilemma}

As already stressed in Sect. 2, the understanding and the formulation of the presented trilemma are deeply grounded in some of the key features of the EMU. In the absence of a political and budgetary union, rules able to guarantee fiscal policy discipline are required. Setting up common rules implies that all member countries have to adhere to them and reduce their freedom in fiscal decisions. Furthermore, members of a monetary union issue debt in a currency that they do not control. As a result, the governments of these countries cannot guarantee that the cash will always be available in order to pay out bondholders at maturity. These elements make countries involved in a monetary union more fragile with respect to negative financial shocks. This should not be the case in "stand-alone countries", i.e. countries outside a monetary union. Consequently, the monetary union trilemma should not apply to stand-alone countries as they do not face common fiscal rules with other countries, issue debt in a currency on which have full control and are not necessarily required to be financially integrated with other countries.

Then, our last exercise in order to assess the robustness of our results is intended to analyze the specificity of the estimated trilemma for the EMU countries. To this aim we test the existence of the trilemma in a group of stand-alone countries (Australia, Japan, Russia, USA and UK) based on indicators (1), (2), and (3). ${ }^{11}$ In order to have a similar benchmark in terms of countries and time, we also present the results of the estimation of Eq. (5) for the EMU countries in our dataset divided in two sub-groups (core and periphery) and spanning the same period covered by the stand-alone countries dataset.

As reported in Table 11, the trilemma still applies to the two EMU sub-groups as the estimated coefficients have positive sign and are statistically significant at $1 \%$. The same does not seem to apply to the panel estimation for the stand-alone

${ }^{11}$ Given data availability, the period covered for these countries is $2000 \mathrm{q} 2-2012 \mathrm{q} 4$. 
Table 12 Specificity of the trilemma (single countries)

\begin{tabular}{llllll}
\hline & Australia & Japan & Russia & USA & UK \\
\hline FPF & $-0.075(0.051)$ & $0.029(0.077)$ & $-0.014(0.049)$ & $0.059(0.043)$ & $0.069(0.061)$ \\
FS & $1.499 * * *(0.021)$ & $1.462 * * *(0.038)$ & $1.596^{* * *}(0.037)$ & $1.541^{* * *(0.018)}$ & $1.509 * * *(0.015)$ \\
FCM & $0.014(0.035)$ & $332.891 * * *(90.781)$ & $0.208^{* * *}(0.07)$ & $-2.995(42.785)$ & $-1.328(5.042)$ \\
\hline
\end{tabular}

$* * *$ Indicates level of significance at $1 \%$, no asterisk indicates no significance at $10 \%$. Standard errors in parentheses

countries because statistical significance is not confirmed for all of the estimated coefficients. This suggests the rejection of the trilemma for such countries. In order to further investigate this aspect, we also perform single countries estimations of the trilemma equation in the stand-alone group. The results from such estimations are reported in Table 12 and they strengthen the evidence from the panel regression as the negative estimated coefficients strongly deny the suitability of the trilemma for this group of stand-alone countries.

Then, thanks to this specific additional analysis, we have also provided evidence of the fact that the trilemma seems to be specifically working for countries in the EMU and policymakers of stand-alone countries should not be confronted with such a policy objectives trade-off.

\section{Conclusion}

The recent economic turmoil in the Eurozone has called interest on the interactions between financial markets and fiscal policy and has stressed the difficulties in reconciling the contemporaneous existence of capital market integration, financial stability and the ability to manage fiscal accounts.

In this paper we have contributed to this literature by empirically investigating the existence of a policy trilemma faced by member countries of the Eurozone involving free capital mobility, financial stability and fiscal policy flexibility. To this aim, we have estimated the existence and the configuration of such a trade-off in a panel of 11 EMU member countries by adopting the methodology introduced by Aizenman et al. (2008) together with other alternative methods proposed in the literature.

The existence of such a trade-off has been proven for both the entire panel and single member countries in the dataset. The estimated trilemma implies that member-countries face a trade-off between the three policy objectives and that they cannot fully achieve free capital mobility, financial stability and fiscal policy flexibility contemporaneously. In terms of the trilemma configuration, we have shown that member states have mainly focused on financial stability and have minimized fiscal policy flexibility whenever possible. Nevertheless, our results suggest that during the crisis financial stability has decreased and fiscal policies have been more oriented towards national objectives. 
Although our results on the configuration and time variation of the trade-off certainly require future additional research, the result concerning the existence of the trilemma is of paramount importance in itself. This is due to the fact that the existence of such a policy trilemma can be considered as an additional factor supporting the ongoing reforms of the governance of the EMU aiming at safeguarding economic stability. The reforms regarding the banking union, the prudential supervisory role of the ECB and the provision of a lender of last resort are intended to weaken the influence of financial markets on fiscal policies, reduce financial instability and minimize the risk of self-fulfilling crises (see Obsfield 2013; Pisani-Ferry 2012; De Grauwe 2011). Then, under these circumstances, beneficial effects for the Eurozone should be guaranteed also in terms of the trade-off analyzed in this paper.

Acknowledgements The authors would like to thank the editor, Cédric Tille, and two anonymous referees for their constructive comments and helpful suggestions.

Open Access This article is distributed under the terms of the Creative Commons Attribution 4.0 International License (http://creativecommons.org/licenses/by/4.0/), which permits unrestricted use, distribution, and reproduction in any medium, provided you give appropriate credit to the original author(s) and the source, provide a link to the Creative Commons license, and indicate if changes were made.

\section{References}

Aizenman, J., Chinn, M. D., \& Ito, H. (2008). Assessing the emerging global financial architecture: Measuring the trilemma's configurations over time. (NBER Working Papers 14533). National Bureau of Economic Research, Inc.

Aizenman, J., Chinn, M. D., \& Ito, H. (2013). The "Impossible Trinity" hypothesis in an era of global imbalances: Measurement and testing. Review of International Economics, 21(3), 447-458.

Aizenman, J., Chinn, M. D., \& Ito, H. (2015). Monetary policy spillovers and the trilemma in the new normal: periphery country sensitivity to core country conditions. (NBER Working Paper No. 21128). National Bureau of Economic Research, Inc.

Aizenman, J., \& Ito, H. (2014). Living with the trilemma constraint: Relative trilemma policy divergence, crises, and output losses for developing countries. Journal of International Money and Finance, 49, 28-51.

Ardagna, S. (2009). Financial markets' behaviour around episodes of large changes in the fiscal stance. European Economic Review, 53, 37-55.

Brave, S., \& Butters, R. A. (2011). Monitoring financial stability: A financial conditions index approach. Economic Perspectives (Federal Reserve Bank of Chicago) 35(Q1), 22-43.

Brunila, A., Buti, M. \& in't Veldt, J. (2002). Fiscal policy in Europe: How effective are automatic stabilisers? (European Commission Economic Papers, No. 177), September.

Cortuk, O., \& Singh, N. (2013). Turkey' trilemma trade-offs: Is there a role for reserves? Íktisat Issletme ve Finans, 28(328), 105-122.

Davidson, R., \& MacKinnon, J. G. (1981). Several tests for model specification in the presence of alternative hypotheses. Econometrica, 49, 781-793.

De Grauwe, P. (2011). The European Central Bank as a lender of last resort. Vox. http://www.voxeu.org/ article/european-central-bank-lender-last-resort. Accessed 1 Feb 2015.

De Grauwe, P., \& Ji, Y. (2013). From panic-driven austerity to symmetric macroeconomic policies in the eurozone. Journal of Common Market Studies, 51(Issue Supplement S1), 31-41.

Duprey, T., Klaus, B., \& Poltonen, T. (2015). Dating systemic financial stress episodes in the EU countries. (ECB Working Paper Series, No. 1873), December. 
Fernández, A., Klein, M., Rebucci, A., Schindler, M., \& Uribe, M. (2016). Capital control measures: A new dataset. IMF Economic Review, 64, 548-574.

Fleming, J. M. (1962). Domestic financial policies under fixed and floating exchange rates. IMF Staff Papers 9, 369-379. Reprinted in R. N. Cooper, Ed., 1969, International Finance, New York: Penguin Books.

Foresti, P., \& Napolitano, O. (2017). On the stock market reactions to fiscal policies. International Journal of Finance and Economics. https://doi.org/10.1002/ijfe.1584.

Geršl, A., \& Heřmánek, J. (2008). Indicators of financial system stability: Towards an aggregate financial stability indicator? Prague Economic Papers, 2, 127-142.

Hollo, D., Kremer, M., \& Lo Duca, M. (2012). CISS-A composite indicator of systemic stress in the financial system. (ECB Working Paper No. 1426).

Hsing, Y. (2012). Impacts of the trilemma policies on inflation, growth and volatility in Greece. International Journal of Economics and Financial Issues, 2(3), 373-378.

Hutchison, M., Sengputa, R., \& Singh, N. (2012). India's trilemma: Financial liberalization, exchange rates and monetary policy. World Economy, Special Issue: India, 35(1), 3-18.

Illing, M., \& Liu, Y. (2003). An index of financial stress for Canada. (Bank of Canada Working Papers 14). June.

IMF. (2009). Balance of payments and international investment position manual (6th ed.). Washington, DC: International Monetary Fund.

Ingram, J. C. (1962). Regional payment mechanisms: The case of Puerto Rico. Chapel Hill: University of North Carolina Press.

Ito, H. \& Kawai, M. (2014). Determinants of the trilemma policy combination. (ADBI Working Paper Series, No. 456), January.

Jakubík, P., \& Slačík, T. (2013). How to measure financial (in)stability in emerging Europe? (Working Papers IES 2013/13). Charles University Prague, Faculty of Social Sciences, Institute of Economic Studies, September.

Lane, P., \& Milesi-Ferretti, G. M. (2003). International financial integration. IMF Staff Papers, Vol. 50, Special Issue, International Monetary Fund.

Lane, P., \& Milesi-Ferretti, G. M. (2006). The external wealth of nations mark II: Revised and extended estimates of foreign assets and liabilities. Journal of International Economics, 73(November), $223-250$.

McKinnon, R. (2004). Optimum currency areas and key currencies: Mundell I versus Mundell II. Journal of Common Market Studies, 42(4), 689-715.

Mundell, R. A. (1963). Capital mobility and stabilization policy under fixed and flexible exchange rates. Canadian Journal of Economic and Political Science, 29(4), 475-485. https://doi.org/10.2307/ 139336. Reprinted in R. A. Mundell, (1968), International economics. New York: Macmillan.

Mundell, R. (1973a). Uncommon arguments for common currencies. In H. Johnson \& A. Swoboda (Eds.), The economics of common currencies (pp. 114-132). London: Jeorge Allen \& Unwin.

Mundell, R. (1973b). A plan for a European currency. In H. Johnson \& A. Swoboda (Eds.), The economics of common currencies (pp. 143-172). London: Jeorge Allen \& Unwin.

Nelson, W., \& Perli, R. (2005). Selected Indicators of Financial Stability. Irving Fisher Committee's Bulletin on Central Bank Statistics, 23, 92-105.

Obstfeld, M. (2013). Finance at a center stage: Some lessons for the euro-crisis. (European Economy, Economic Papers 493), April.

Pisani-Ferry, J. (2012). The euro crisis and the new impossible trinity. Bruegel Policy Contribution 2012/01, January.

Sales, A.S., Areosa, W. D., \& Areosa, M. B. M. (2012). Some financial stability indicators for Brazil. (Banco Central do Brasil Working Paper Series 287). July.

Schindler, M. (2009). Measuring financial integration: A new data set. IMF Staff Papers, 56(1), 222-238. Tukey, J. W. (1962). The future of data analysis. Annals of Mathematical Statistics, 33(1), 1-67. 